\title{
Doctors' orders, rationality and the good life: commentary on Savulescu
}

\author{
John Harris University of Manchester, Manchester
}

In his paper, Should doctors intentionally do less than the best, ${ }^{1}$ Julian Savulescu makes a number of controversial and interesting claims. They have to do with the nature of rationality, the obligations of doctors and the significance of genetic relatedness. I will concentrate on rationality and the obligations of doctors. What Savulescu has to say about the significance of genetic relatedness seems broadly correct, although I do not believe he has taken on board its significance when related to the other parts of his overall position, as we shall see.

\section{The obligations of doctors}

Savulescu is concerned with what doctors should do. No one doubts that this is a matter for individual conscience. However, in a world in which doctors have a monopoly on the power and privilege to carry out many technical procedures, they must either give up their privileges or learn more tolerance of eccentricity and frivolity.

Savulescu asks: "Are there ever occasions in which doctors should actively participate in bringing about less than the best outcome?" And answers: only when doctors have "most reason to do what these parents and patients are requesting"; and that is only when what patients or parents want will promote "some objectively valuable state such as wellbeing, achievement, knowledge, justice and so on". ${ }^{1}$

Unless "wellbeing" is to be interpreted, very widely, as anything that will make patients or parents happy, this is very restrictive indeed. It makes doctors' decisions more important than patients' wishes or rights. This, as I have indicated, is fine so long as patients can implement legitimate wishes and rights via channels other than doctors. But when, as now, doctors have a monopoly over many procedures, assisted reproduction being a clear case, patients have no alternatives.

The idea of having "a good reason to have a child" seems bizarre. Many people (perhaps a majority of the world's population) have children without any particular thought or reason, knowing that the children's circumstances will be suboptimal. When Savulescu asks: "How should doctors respond when individuals request medical assistance to bring about an outcome that is less than optimal?" and replies that they may so respond "but only if there is good reason to do so", he does not count respecting freedom of choice as one such reason. Only choices which promote "objectively valuable" states will do. From what he says it looks as though sub-optimal states will never be objectively valuable unless some morally serious value can be shown to be at stake. It follows that in assisted reproduction (and in industrialised countries almost all reproduction is medically assisted to some extent) the poor should not be helped, neither should those who want extra children whose birth will decrease the total wellbeing of the family, nor should anyone be helped to have a genetic child when there are equally healthy babies waiting for adoption, nor should anyone be allowed to keep a second child while any infertile people who want children remain childless.

This may all be morally defensible, but doctors who pursued such an ethic would soon find another profession had been allocated the right to assist medically with procreation.

\section{Rationality}

Savulescu's concern with what doctors should do turns on a theory of choice according to which:

For a choice to be rational, the state of affairs promoted by that choice or act must be worth promoting. That is, it must promote some objectively valuable state such as wellbeing, achievement, knowledge, justice and so on.

This is all very noble, but a long way from any ordinary understanding of rationality; so far indeed, that to purport, for theoretical purposes, to harness the powerful "field of force" exerted by a term such as "rationality" stretches the word beyond breaking point. It cannot be irrational to choose something desirable but worthless, like designer water or pulp fiction, for example. It might be "unworthy" but it is not "irrational" if that is what you fancy; unless some complex story is told as to how such choices might be self-defeating, or inconsistent with other aims the agent has. It cannot even be irrational to choose 
such things in preference to more objectively valuable objects of choice, like pre-phyloxera claret or Tolstoy. Unless of course one irrationally believes that designer water is pre-phyloxera claret, or that Tolstoy wrote pulp fiction.

This, clearly obsessive, ${ }^{2}$ high-mindedness leads Savulescu to misunderstand the position Burley and I take. ${ }^{3}$ We imagine someone who prefers a mixed-race marriage even though, because they live in a racially prejudiced society, they know their children will be less well off than the children either would have had if they had opted for a same-race marriage with a different partner. Savulescu, gratuitously interprets the couple's motives: "but they want to make a political statement about racial equality .... This is a good reason to have a black child". With respect to Savulescu, this is not what they want and, in our submission, they don't need a good reason. They just want kids with someone they love best.

\section{Objective value}

Savulescu wants to say that where a sub-optimal outcome is chosen by parents this must be irrational, and moreover doctors cannot have "most reason" to do what parents want unless their choice is rational (morally serious or objectively valuable) in his sense. But political liberty is nothing if it is subject always to the passing of some externally imposed test of "objective value". We can see this if we consider again the miscegenation case Burley and I posited. Jane and Dick want to have a child who will in all probability be healthy and will certainly be loved by its parents. They are of different races and live in a racist society. Because the racism of others will make their child's life sub-optimal, Savulescu's position suggests they should not procreate; and doctors should not help them to do so unless Jane and Dick want to make some anti-racist and worthy statement. If they want, as do the real Jane and Dick, simply to be left alone to have "their" child then, according to Savulescu, their procreational liberty is not protected and doctors should not assist them.

Suppose the society in which Jane and Dick live is not against marriage between races but "simply" against the production of mixed-race children. Then, since Savulescu also believes that genetic relatedness is not important, Jane and Dick should accept donor sperm, or adoption for example, as ways of avoiding producing a mixedrace child.

I think Savulescu is right about the unimportance of genetic relatedness, but wrong in so far as he seems to think that choices which are not "objectively valuable" are irrational and therefore beyond the protection of any principle of politican liberty. Of course Savulescu could say that eve though fighting racism is not the parents' motive for having children it is a motive they would hav "if they knew the relevant facts and were thinkin clearly". ${ }^{4}$ So let's take another less political case.흐

In an IVF clinic doctors have ten embryos in the fridge provided by Doris for her future treatmen $\frac{\mathbb{B}}{9}$ Doris is very poor and her children, if she has ants will be disadvantaged compared with those of Hermione, who is very rich and can give her chil dren every advantage, but has produced n $\vec{\infty}$ embryos. We know that poverty is one of the most reliable predictors of sub-optimal outcomes for children, so that, other things being equal, it almost always doing "less than the best" to helipo the poor to procreate. Since we know from Savito lescu that genetic relatedness is not important doctors should not consider the question of whose embryos they are at all significant. They must decide what would be best overall for the resulting. child. They should transfer the embryos to Hermione. $^{5}$

Although I agree with Savulescu that genetic relatedness is not important I think procreative liberty is, even though it may result in sub-optima outcomes for children. ${ }^{6}$ Of course Savulesca could value procreative liberty and if he did, ho theory of reasons for action would support Doris not Hermione.

In Savulescu's scheme as he himself interprets it, freedom would always be in pawn to prejudic wherever the bigots threatened to make life difficult, then those who want to live a quiet but free life would have no liberty, and doctors, (sinces according to Savulescu, they should not in such circumstances "intentionally do less than the best"), would not be at liberty to assist them. There are always a number of different ways in which outcomes can be maximised from the point of view of utility. In the cases we are considering; one is to give way to immoral pressure; the oth is to fight it. Fighting it may be more problematio from the point of view of outcomes for the nexp generation, particularly where the bigots are in majority and likely to remain so. But it is surely perverse reading of consequentialism to suppos that doctors must connive at racism unless the parents themselves have anti-racist reasons for their choice of procreative path. If political liber is to mean anything it must protect the freedom of the ordinary citizen who wants a quiet life and h $\mathbb{B}$ or her private choices to be just that, and whig would not wish to make and have to defend a "political statement". Someone who simply want the freedom to do ordinary, even silly things, is 
entitled to the protection of a principle of liberty as is anyone else.

When Savulescu says of our miscegination case: "but they want to make a political statement about racial equality .... This is a good reason to have a black child", he implies that a bad reason to have a black child - "I prefer the colour", would not be protected unless it also constitutes resistance to racism. But it is our position that even where it would not constitute resistance to racism, people should be free to choose their procreational partner. Even if people want black children because "black is beautiful" that is enough. As Ronald Dworkin has memorably remarked in another context: "No one may be prevented from influencing the shared moral environment, through his own private choices, tastes, opinions, and example, just because these tastes or opinions disgust those who have the power to shut him up or lock him up."7
Fohn Harris is Sir David Alliance Professor of Bioethics, and a Director of the Centre for Social Ethics and Policy and of the Institute of Medicine, Law and Bioethics, University of Manchester.

\section{References and notes}

1 Savulescu J. Should doctors intentionally do less than the the best? Fournal of Medical Ethics 1999;25:121-6.

2 And hence "irrational"?

3 Burley J, Harris J. Human cloning and child welfare. fournal of Medical Ethics 1999;25:108-13.

4 See Savulescu J. Consequentialism, reasons, value and justice. Bioethics 1998;12:212-35.

5 To avoid muddying the waters with contractual issues we'll assume that the doctors who have to make these decisions have taken over the clinic after all previous doctors perished in an epidemic of existential angst, and that there exist no actual or implied contracts with either Hermione or Doris.

6 There is of course a threshold of sub-optimality beyond which procreative choices will become morally problematic. See reference 3.

7 Dworkin R. Freedom's law. Oxford: Oxford University Press, 1996: 237-8.

\section{News and notes}

\section{BIOETHICSLINE now free on web}

BIOETHICSLINE, an online database with almost 60,000 references to English language bioethics literature can now be searched via the web at no charge. Accessed at http://guweb.georgetown.edu/nrcbl/ this database is useful to anyone looking for documents encompassing ethical, legal, or public policy aspects of health care or biomedical research. BIOETHICSLINE spans the literature of the health sciences, law, religion, philosophy and the social sciences.

Produced by the Information Retrieval Project at Georgetown University's Kennedy Institute of Ethics, BIOETHICSLINE is part of the National Library of Medicine's MEDLARS system of searchable databases available on the world wide web. Internet Grateful
Med provides structured search features and online guidance.

Easy to search by subject, the new web site can be accessed by subject, title or author. Terms can be combined, searches may be limited to specific types of literature and by year to produce citations that are specific to the topics needed by the searcher. Additional bioethical information is available at the web site: a Bioethics Thesaurus and Searchers' Guide provide assistance as well as links to other pertinent bioethics sites.

A toll-free telephone number, 800-MED-ETHX (800-633-3849; in DC 202-687 3885), may be called for further information or for assistance web searching. 